\title{
Development of IDF Curves for Colombo
}

\author{
K.D.W. Nandalal and P. Ghnanapala
}

\begin{abstract}
Rainfall Intensity-Duration-Frequency (IDF) relationships usually play a major role in the designing and building of water infrastructure. The main purpose of this paper is to show the procedure that need to be followed in the development of IDF relationships using rainfall data collected in Colombo, Sri Lanka. Short duration rainfall data of Colombo recorded over a 30 year period by the Department of Meteorology were used for the study. The procedures to be adopted in screening rainfall data, carrying out frequency analyses, and finally developing the IDF relationships are described. The IDF curves have been developed for 2, 5, 10, 25, 50 and 100 year return periods for durations ranging from 15 minutes to 24 hours. The developed IDF relationships were compared with the IDF relationships presently available for Colombo. The results indicate that the rainfall intensities of Colombo have recently increased. It is recommended that the IDF relationships for other stations in the country also be updated.
\end{abstract}

Keywords: IDF Curve development, Short duration rainfalls, Frequency analysis

\section{Introduction}

Rainfall Intensity-Duration-Frequency (IDF) relationship is widely used in the planning, designing and operation of water resources projects. It is a mathematical relationship among rainfall intensity, duration and return period. It is found to be useful in flood mitigating projects. The development of IDF relationships had been done as early as in 1932 [1]. These relationships are now available for several parts of the globe. The IDF relationships available for the Calabar catchment in Nigeria [2] and Vietnam [3] are some such examples.

However, such relationships are not yet available in most of the developing countries due to the non-availability of sufficiently long historical data sets.

Baghirathan and Shaw [4] carried out rainfall depth-duration-frequency studies for Sri Lanka in respect of 19 stations spread outacross the country. The development of IDF relationships for these 19 stations was based on rainfall data records of 8 to 24 years. With slightly longer data records, Dharmasena and Premasiri [5] also developed IDF curves for several stations in the country. The IDF relationships presented by Ranatunga [6], based on more recent rainfall data, have been used extensively in Sri Lanka. However, with the change in rainfall intensities received over the country, it is of paramount importance to update the IDF relationships using recent rainfall data. This paper presents a method for deriving the IDF relationships for a given location. The method is presented based on the rainfall record of Colombo.

\section{Methodology}

\subsection{Data Collection}

The data related to 15 minute daily rainfall data of Colombo exceeding $10 \mathrm{~mm}$ and collected by the Department of Meteorology, Sri Lanka during a period of 30 years from 1981 to 2010 were used in the study. The 15 minute data were read from the daily charts of a syphon type automatic rainfall recorder installed at the premises of the Meteorological Office in Colombo at latitude $6^{\circ} 54^{\prime} 17^{\prime \prime} \mathrm{N}$ and longitude $79^{\circ} 52^{\prime} 19^{\prime \prime} \mathrm{E}$ approximately. The daily rainfall data over the same period were also collected using a standard rain gauge installed at the same location in Colombo.

\subsection{Data Screening}

The total daily rainfalls obtained for 15 minutes were compared with the daily rainfall data read on a check gauge (standard rain gauge observations made at $0830 \mathrm{~h}$ ). The records which deviated by more than $30 \%$ were considered unreliable and were not considered for the study.

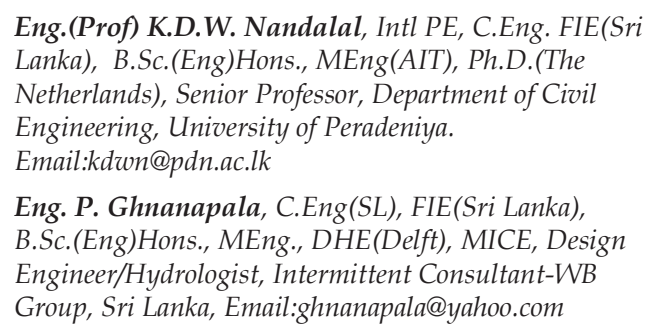


The amount of rainfall that fell for 15, 30, 60, 90, 120, 180, and 240 minutes were compiled using 15 minute rainfall data. The annual maximum and annual exceedance data series were extracted from validated records. The annual exceedance series refer to Peak Over Threshold rainfalls by retaining the $\mathrm{N}$ largest values, where $\mathrm{N}$ is equal to the number of years in the series.

Thereafter, this data were tested for their suitability for use in a frequency analysis. The data screening procedure adopted consisted of the following steps[7].

- Plotting the totals according to the chosen time step and noting any trends or discontinuities

- Testing the time series using Spearman's rank-correlation method to ascertain the absence of trend

- Applying the F-test for checking the stability of variance and the t-test for checking the stability of mean using split, non-overlapping, sub-sets of the time series

- Testing the series for absence of persistence by computing the first serial correlation coefficient

\subsection{Frequency Analysis}

In the frequency analysis, the annual exceedance series was used for more frequent events having return periods upto 10 years (2, 5 and 10 years), while the annual maximum series was used for return periods of 25 years and more (25, 50 and 100 years). It is the practice to use annual exceedance series for return periods upto 10 years and annual maximum series for higher return periods.

The best probability distribution among GEV, Weibull, Frechet and Gumbel distributions was found for both the annual exceedance series and the annual maximum series. Thereafter, using the best fitting distribution, rainfall intensities for different return periods were calculated for all rainfall durations. Corrections were made to fixed/restricted $15 \mathrm{~min}$ data according to the guidelines developed by Dwyer and Reed, when converting them to sliding/unrestricted data [8]. The correction factors used were 1.160, $1.085,1.026,1.008$ and 1.003 respectively for 15 ,
30 60, 90 and 120 minute duration rainfall data [8].

\section{Development of Intensity- Duration-Frequency Relationships}

The development of IDF relationships commenced with the comparison of daily total rainfalls determined from 15 minute data with the daily rainfalls obtained from the check gauge. During this process, the annual maximum records of five years $(1983,1987$, 1989, 2000 and 2010) had to be discarded since their deviations were more than $30 \%$. The percentages of data that deviated upto $10 \%$, $10 \%$ to $20 \%, 20 \%$ to $30 \%$ and more than $30 \%$ were found to be $81 \%, 7 \%, 4 \%$ and $8 \%$, respectively. This shows that the number of rainfall records that have shown considerable deviations in the total daily rainfalls is very small. In general, rainfall records upto a deviation of $20 \%$ did not affect the annual maximum rainfalls.

After completing the data screening procedure, the determination of rainfall depths at different return periods was carried out. For this, the probability distribution that best fitted the data series had to be found. The GEV, Weibull, Frechet and Gumbel probability distributions were thus tested to ascertain their suitability in this regard. The GEV distribution was observed to be the best fitting distribution for both annual exceedance series and the annual maximum series.

Thereafter from the best fitting distribution (GEV distribution), rainfall intensities for different return periods were calculated for all rainfall durations and the corrections to the fixed/restricted 15 minute data were incorporated when converting them to sliding/ unrestricted data.

The rainfall data for different durations and different return periods after incorporating the corrections are given in Table 1. Figures1 and 2 present the relationships of rainfall depth with rainfall duration and return period. 
Table 1 - Rainfall depths for different durations and different return periods (mm)

\begin{tabular}{rrrrrrr}
\hline $\mathrm{D}(\mathrm{min})$ & $2 \mathrm{yr}$ & $5 \mathrm{yr}$ & $10 \mathrm{yr}$ & $25 \mathrm{yr}$ & $50 \mathrm{yr}$ & $100 \mathrm{yr}$ \\
\hline 15 & 38.84 & 45.54 & 50.78 & 58.92 & 63.68 & 68.17 \\
30 & 59.10 & 67.97 & 74.18 & 84.01 & 89.67 & 94.84 \\
60 & 79.20 & 91.83 & 101.65 & 117.35 & 126.15 & 134.31 \\
90 & 90.01 & 105.39 & 116.57 & 133.05 & 147.65 & 160.62 \\
120 & 96.48 & 113.95 & 127.20 & 147.18 & 161.18 & 175.59 \\
180 & 102.99 & 123.51 & 142.16 & 179.05 & 203.90 & 230.31 \\
240 & 109.43 & 135.18 & 159.04 & 205.31 & 243.43 & 287.15 \\
\hline
\end{tabular}

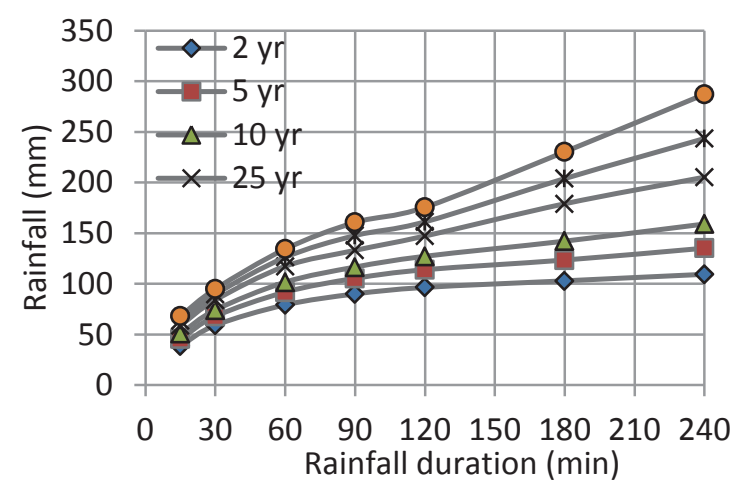

Figure 1 - Rainfall against rainfall duration

These rainfall depths were compared with the rainfall depths provided in two of the previous studies and the results are presented in Table 2. One of the studies was by D \& P [5], who used the same raw data set for the period from 1960 to 1985. In their study, the Extreme Value Type I (EVI) (Gumbel) Distribution was fitted to the annual maximum rainfall series. The other study was by JICA [9], which used results of a study reportedly carried out by $\mathrm{H}$. Humphrey listing from 1921 to 1967all high

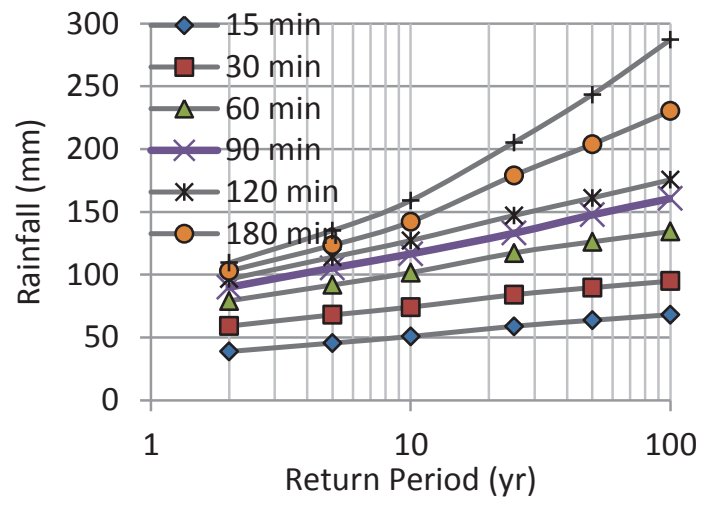

Figure 2 - Rainfall against return period

intensity storm rainfall data for 15, 30, 45, 60, 75, and 90 minutes. As the report mentions, these data have been read directly from the original daily charts of the automatic rainfall recorder at the Colombo observatory. Based on these data, the probable rainfalls were estimated for the given durations and frequencies. The rainfall has increased slightly compared to what is mentioned in the previous studies.

Table 2 - Comparison of rainfalls derived in this study with those of two previous studies

\begin{tabular}{lllrrrrr}
\hline \multirow{2}{*}{$\begin{array}{l}\text { Rainfall } \\
\text { Duration }\end{array}$} & Study & \multicolumn{7}{c}{ Return Period } \\
\cline { 2 - 7 } 15 min & Present & 38.8 & 45.5 & 50.8 & 58.9 & 63.6 & 68.2 \\
& D\&P & 31.8 & 36.8 & 39.9 & 45.0 & 48.5 & 51.8 \\
& JICA & 31.0 & 36.4 & 40.0 & na & na & na \\
\hline \multirow{2}{*}{30 min } & Present & 59.1 & 68.0 & 74.2 & 84.0 & 89.7 & 94.8 \\
& D\&P & 51.3 & 64.0 & 71.4 & 80.0 & 86.9 & 94.0 \\
& JICA & 51.0 & 62.7 & 70.5 & na & na & na \\
\hline \multirow{2}{*}{60 min } & Present & 79.2 & 91.8 & 101.7 & 117.4 & 126.2 & 134.3 \\
& D\&P & 72.9 & 91.9 & 102.4 & 116.3 & 127.5 & 138.4 \\
& JICA & 72.6 & 90.4 & 102.1 & na & na & na \\
\hline \multirow{2}{*}{90 min } & Present & 90.0 & 105.4 & 116.6 & 133.0 & 147.7 & 160.6 \\
& D\&P & 76.4 & 95.0 & 105.2 & 121.2 & 132.4 & 143.9
\end{tabular}




\begin{tabular}{rlrrrrrr} 
& JICA & na & na & na & na & na & na \\
\hline \multirow{2}{*}{120 min } & Present & 96.5 & 114.0 & 127.2 & 147.2 & 161.2 & 175.6 \\
& D\&P & 79.0 & 96.0 & 108.0 & 124.0 & 135.9 & 148.1 \\
& JICA & na & na & na & na & na & na \\
\hline \multirow{2}{*}{180 min } & Present & 102.9 & 123.5 & 142.2 & 179.1 & 203.9 & 230.3 \\
& D\&P & 93.5 & 118.1 & 132.1 & 153.5 & 168.1 & 183.7 \\
& JICA & 79.0 & 100.3 & 113.8 & na & na & na \\
\hline \multirow{2}{*}{240 min } & Present & 109.4 & 135.2 & 159.0 & 205.3 & 243.4 & 287.2 \\
& D\&P & 100.5 & 127.4 & 143.2 & 166.9 & 183 & 200.3 \\
& JICA & na & na & na & na & na & na \\
\hline
\end{tabular}

The rainfall intensities calculated from the rainfall depths are given in Table 3 . The IDF curves for the results given in Table 3 are presented in Figure 3.

These rainfall intensities were compared with the rainfall intensities estimated by Ranatunga [6] for Colombo which are given in Table 4.
The differences between the rainfall intensities determined in the present study and the rainfall intensities estimated by Ranatunga [6] are shown in Figure 4 . The differences are given as a percentage difference with respect to the previous study.

Table 3 - Rainfall intensity in $\mathrm{mm} / \mathrm{h}$ at different return periods (sliding data)

\begin{tabular}{rrrrrrr} 
& \multicolumn{3}{c}{ From Annual Exceedance Series } & \multicolumn{3}{c}{ From Annual Maximum Series } \\
\hline $\begin{array}{r}\text { Duration } \\
(\mathrm{min})\end{array}$ & $2 \mathrm{yr}$ & $5 \mathrm{yr}$ & $10 \mathrm{yr}$ & $25 \mathrm{yr}$ & $50 \mathrm{yr}$ & $100 \mathrm{yr}$ \\
\hline 15 & 155.35 & 182.15 & 203.11 & 235.68 & 254.73 & 272.67 \\
30 & 118.21 & 135.94 & 148.35 & 168.01 & 179.34 & 189.67 \\
60 & 79.20 & 91.83 & 101.65 & 117.35 & 126.15 & 134.31 \\
90 & 60.01 & 70.26 & 77.71 & 88.70 & 98.43 & 107.08 \\
120 & 48.24 & 56.98 & 63.60 & 73.59 & 80.59 & 87.79 \\
180 & 34.33 & 41.17 & 47.39 & 59.68 & 67.97 & 76.77 \\
240 & 27.36 & 33.80 & 39.76 & 51.33 & 60.86 & 71.79 \\
\hline
\end{tabular}

Table 4 - Rainfall intensity in $\mathrm{mm} / \mathrm{h}$ at different return periods given in the study by Ranatunga (2001)

\begin{tabular}{rrrrrrr}
\hline \multirow{2}{*}{$\begin{array}{r}\text { Duration } \\
(\mathrm{min})\end{array}$} & $2 \mathrm{yr}$ & $5 \mathrm{yr}$ & $10 \mathrm{yr}$ & $25 \mathrm{yr}$ & $50 \mathrm{yr}$ & $100 \mathrm{yr}$ \\
\cline { 2 - 7 } 15 & 127.82 & 150.01 & 162.81 & 182.15 & 198.02 & 212.00 \\
30 & 96.33 & 115.85 & 126.48 & 143.14 & 155.83 & 167.81 \\
60 & 65.97 & 81.19 & 89.36 & 102.32 & 111.60 & 120.93 \\
90 & 50.91 & 63.36 & 70.13 & 80.79 & 88.24 & 95.94 \\
120 & 41.79 & 52.36 & 58.21 & 67.31 & 73.60 & 80.20 \\
180 & 31.18 & 39.36 & 44.05 & 51.18 & 56.04 & 61.24 \\
240 & 25.12 & 31.85 & 35.81 & 41.73 & 45.75 & 50.08 \\
\hline
\end{tabular}




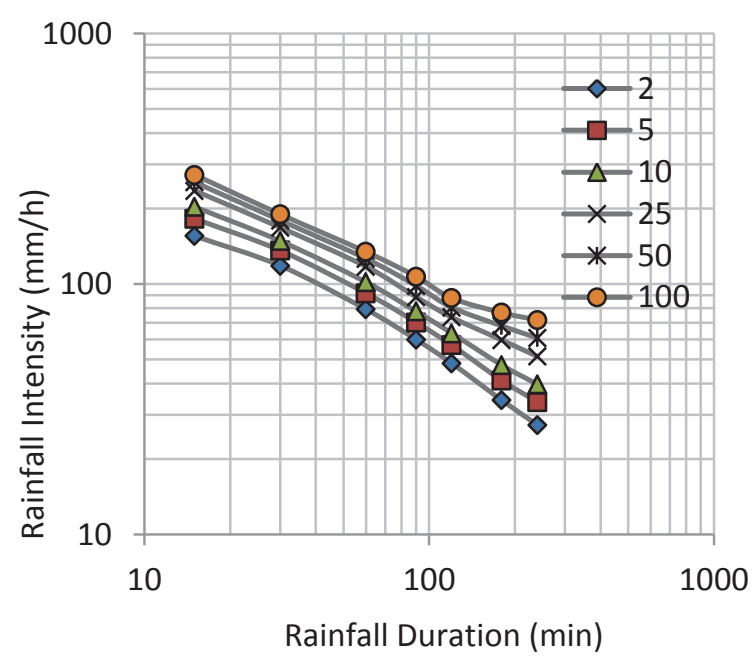

Figure 3 - IDF Curves

The equation best fitting these rainfall intensities (Table 3)was developed using the "shifted power equation" given below.

Rainfall Intensity

$$
=a(\text { rainfall duration }-b)^{C}
$$

where $a, b$ and $c$ are constants. Table 5 gives the values of $a, b$ and $c$ for different return

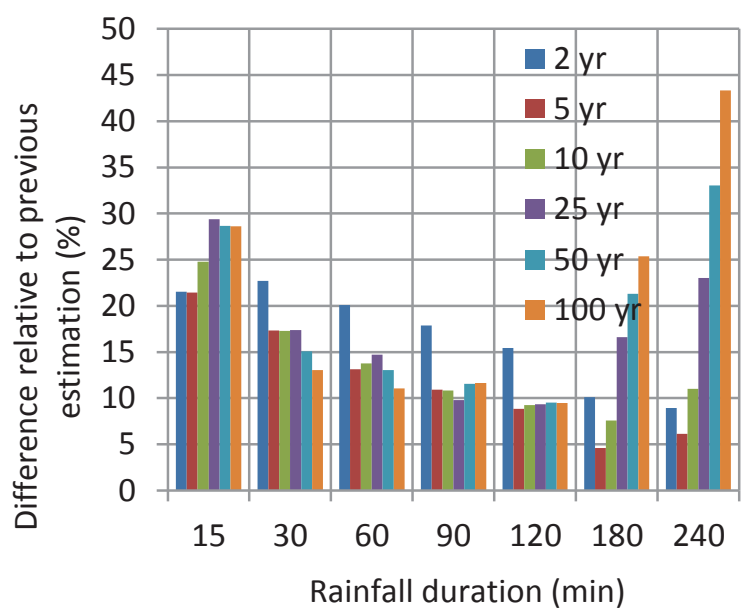

Figure 4 - Difference between rainfall intensities determined in the study and those given by Ranatunga (2001)

periods. The rainfall duration is in minutes and the rainfall intensities are in $\mathrm{mm} / \mathrm{h}$.

The rainfall intensities determined from the above equation are presented in Table 6. The IDF curves developed are given in Figure 5.

Table 5 - Value of constants in the power equation to be used in calculating rainfall intensity

\begin{tabular}{crrrrrr}
\hline Constant & $2 \mathrm{yr}$ & $5 \mathrm{yr}$ & $10 \mathrm{yr}$ & $25 \mathrm{yr}$ & $50 \mathrm{yr}$ & $100 \mathrm{yr}$ \\
\hline $\mathrm{a}$ & 6844.65 & 4383.95 & 2832.77 & 1579.57 & 1124.45 & 831.49 \\
$\mathrm{~b}$ & -31.217 & -22.872 & -15.388 & -5.818 & -0.827 & 3.486 \\
$\mathrm{c}$ & -0.987 & -0.875 & -0.772 & -0.626 & -0.537 & -0.455 \\
\hline
\end{tabular}

Table 6 - Rainfall intensities $(\mathrm{mm} / \mathrm{h})$ of various durations determined for different return periods using the shifted power equation that was fitted

\begin{tabular}{rrrrrrr}
\hline $\begin{array}{r}\text { Duration } \\
(\mathrm{min})\end{array}$ & $2 \mathrm{yr}$ & $5 \mathrm{yr}$ & $10 \mathrm{yr}$ & $25 \mathrm{yr}$ & $50 \mathrm{yr}$ & $100 \mathrm{yr}$ \\
\hline 15 & 155.49 & 182.14 & 202.96 & 235.86 & 255.11 & 273.32 \\
30 & 117.81 & 136.01 & 148.90 & 167.89 & 178.33 & 186.96 \\
60 & 79.46 & 91.77 & 100.63 & 114.69 & 123.79 & 132.47 \\
120 & 48.24 & 56.97 & 64.04 & 76.43 & 85.62 & 95.29 \\
180 & 34.69 & 41.92 & 48.24 & 59.86 & 68.95 & 78.87 \\
240 & 27.10 & 33.41 & 39.23 & 50.24 & 59.12 & 69.03 \\
300 & 22.25 & 27.91 & 33.33 & 43.81 & 52.46 & 62.28 \\
360 & 18.87 & 24.04 & 29.14 & 39.16 & 47.58 & 57.27 \\
720 & 9.91 & 13.46 & 17.34 & 25.50 & 32.81 & 41.67 \\
1080 & 6.73 & 9.52 & 12.75 & 19.81 & 26.39 & 34.62 \\
1440 & 5.10 & 7.44 & 10.23 & 16.56 & 22.62 & 30.36 \\
\hline
\end{tabular}




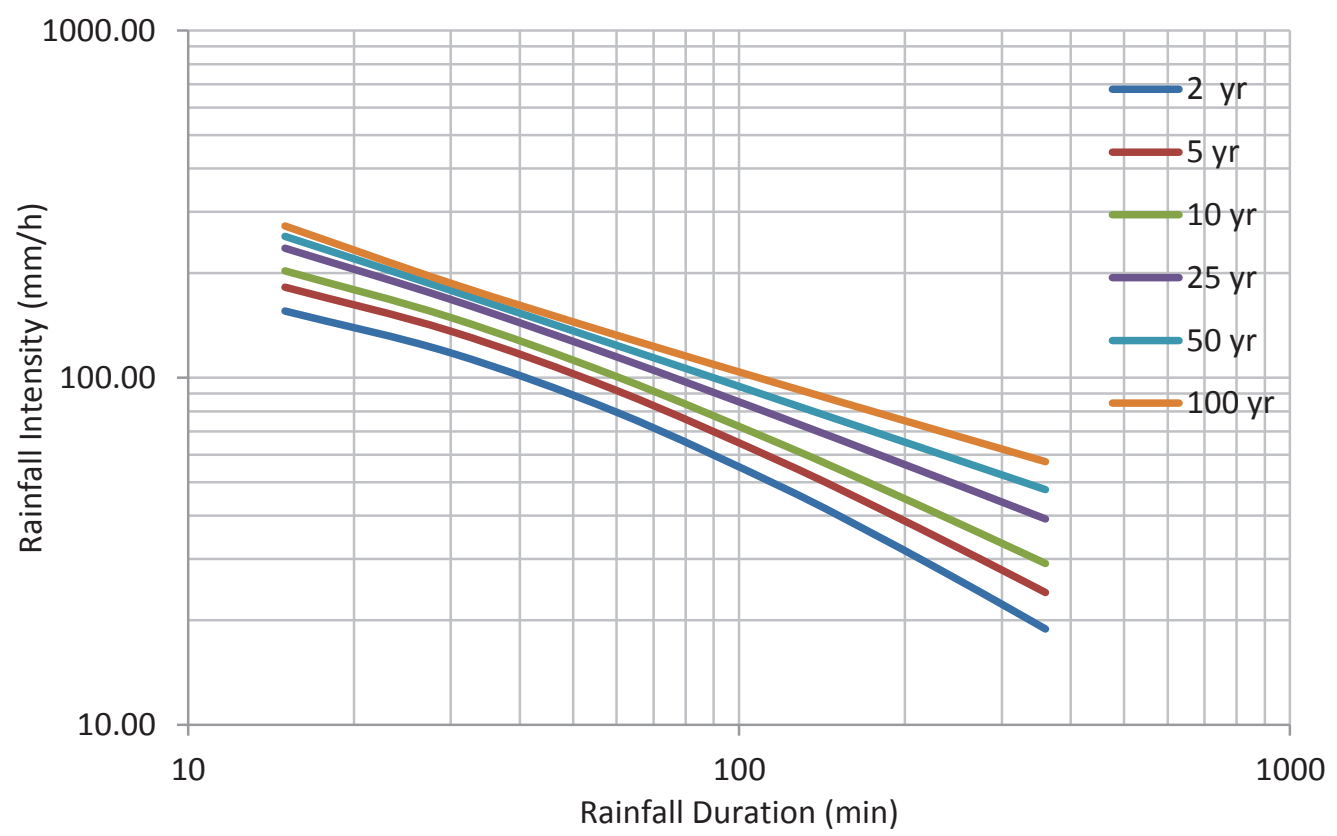

Figure 5 - IDF Curve for Colombo developed based on shifted power equation that was fitted

Table 7 presents the top 3 highest rainfall rates found in the data record for different rainfall durations. The years in which these rainfall rates were observed are given in parenthesis.

Table 7 - Top 3 highest rainfall rates observed at different durations

\begin{tabular}{|r|r|r|r|}
\hline $\begin{array}{c}\text { Duration } \\
\text { (min) }\end{array}$ & \multicolumn{3}{|c|}{ Three highest rainfall rates $(\mathrm{mm} / \mathrm{h})$} \\
\hline 15 & $203.24(1999)$ & $199.56(1985)$ & $179.80(2010)$ \\
\hline 30 & $175.56(2010)$ & $139.92(1998)$ & $134.68(1984)$ \\
\hline 60 & $132.19(2010)$ & $105.39(2000)$ & $99.77^{\prime}(2007)$ \\
\hline 90 & $103.64(2010)$ & $81.61(1992)$ & $74.11^{\prime}(2007)$ \\
\hline 120 & $79.58(2010)$ & $75.10^{\prime}(1992)$ & $60.64(1988)$ \\
\hline 180 & $74.02(1992)$ & $54.46^{\prime}(2010)$ & $49.53(2009)$ \\
\hline 240 & $65.66^{\prime}(1992)$ & $49.48(2009)$ & $41.97(2010)$ \\
\hline
\end{tabular}

The highest rainfall rates have occurred generally in the year 2010. Their return periods vary from 5 years to 90 years.

\section{Conclusions}

This paper presents the procedure to be adopted in developing an IDF curve. The IDF curves developed for the Colombo station show that the rainfall intensities have increased of late. For durations exceeding 90 minutes, this increase could approximately range from 10 to $30 \%$. The increase in intensity for 15 minute duration rainfalls is observed to be considerably high. It is important to consider these increases when designing water management infrastructure. Thus, the updating of the presently available IDF relationships for those locations where short duration rainfall is available is undoubtedly essential.

\section{Acknowledgements}

Contributions made by Mr. H.M.J. Ognik and Mr. S. Wijesundera of the World Bank, Ms. S.M.C.K. Subasinghe of the Lanka Hydraulics Institute and Ms. M.C.U.D.P. Thusari of the Sri Lanka Land Reclamation and Development Corporation during the study are highly appreciated.

\section{References}

1. Bernard, M. M. "Formulas for Rainfall Intensities of Long Duration", Transactions, ASCE, 96 (Paper No.1801), 1932, pp. 592624.

2. Antigha, R. E. \& Ogarepke, N. M. Development of Intensity Duration Frequency Curves for Calabar Metropolis, South-South, Nigeria, The International Journal of Engineering and Science, Vol 2, Issue 3, 2013, pp.39-42.

3. Nhat, Le Minh, Tachikawa, Y \& Takara, K. "Establishment of Intensity-DurationFrequency Curves for Precipitation in the Monsoon Area of Vietnam", Annals of Disaster Prevention Research Institute, Kyoto University, 2006, No.49 B. 
4. Baghirathan, V. R. \& Shaw, E. M. "Rainfall Depth-Duration-Frequency Studies for Sri Lanka", Journal of Hydrology, Vol.37, Issue 34, 1978, pp.223-239.

5. Dharmasena, G. T. \& Premasiri, S. M. "Rainfall Intensity Studies for Sri Lanka", Engineer, Journal of the Institution of Engineers, Sri Lanka, December, 1990, pp.38-52.

6. Ranatunga, D. G. L., (2001) “Towards More Efficient Hydraulic and Hydrological Design of Cross Drainage Structures using New Developed Intensity Duration Frequency Equations", Transactions 2001, Volume I - Part B, The Institution of Engineers, Sri Lanka 2001, pp.01-12.

7. Dahman, E. R. and Hall, M. J. (1990) Screening of Hydrological Data: Tests for Stationarity and Relative Consistency, IILRI, The Nethrlands.

8. Dwyer, I. J. \& Reed, D. W. “Allowance for Discretization in Hydrological and Environmental Risk Estimation (ADHERE)", Report No.13, Institute of Hydrology, Wallingford, 1995, UK.

9. Nippon Koei "The Study on Storm Water Drainage Plan for the Colombo Metropolitan Region in the Democratic Socialist Republic of Sri Lanka. Volume I: Executive Summary. Volume II: Main Report. Volume III: Supporting Report 1: Master Plan. Volume IV: Feasibility Study and Volume V: Data Book", 2003. 